\title{
Thermal variations of water in the Nam Song stream/Mekong River: II. Experimental data and theoretical predictions
}

\author{
Koshi Yoshida $^{1} \cdot$ Sho Shiozawa $^{2} \cdot$ Jiftah Ben-Asher $^{3}$
}

Received: 25 March 2015/Accepted: 1 March 2016/Published online: 19 March 2016

(C) Springer International Publishing Switzerland 2016

\begin{abstract}
The goals of this study were to use the Nam Song River as a case study for parameters determination and a comparison between the measured data and the mathematical model developed in the first paper of this study. The kinematic wave equation [especially Eq. 16a in Ben-Asher et al. (Sustain Water Resour Manag, 2016. doi:10.1007/s40899-016-0044-9)] was expanded to a Taylor series that was used to determine several system parameters including the thermal time constant, the steady state solution, and the daily thermal cycle. Water temperature measured and calculated by the model varied from minimum of $23-24{ }^{\circ} \mathrm{C}$ at night to maximum of $27-29{ }^{\circ} \mathrm{C}$ at midday. From March 16 to March 25 2004, stream and air temperature were monitored at a point located $4 \mathrm{~km}$ downstream from the Nam Song Dam. The average hourly water temperature and its standard deviation were extracted from a family of daily sinusoidal curves. Monitoring downstream data were similar to results assumed by the theoretical model. The effect of water discharge rate on its temperature and on the changing energy input during daytime hours was considered. The analysis indicated that the only controllable system variable is the water flow velocity $(V)$. It can be optimized through a controlled release of water from the dam. The mathematical analysis
\end{abstract}

Jiftah Ben-Asher

benasher@bgu.ac.il

1 Ibaraki University, Chuo 3-21-1, Ami, Ibaraki 300-0393, Japan

2 The University of Tokyo, 7 Chome-3-1 Hongo, Bunkyo, Tokyo 113-8657, Japan

3 The Katif Research Center for Coastal Desert Development, Ministry of Science, Ben-Gurion University of the Negev, Beer Sheva, Israel also identified and quantified the parameters which govern the water environment. The theory as well as the experimental data indicated that for the conditions studied, an increase in water discharge at the dam prevents an increase in water temperature downstream and thus helps to keep the fisheries and domestic water quality of the river in a healthier condition.

Keywords Dams - Climate impacts · Energy budgets . Flow velocity

\section{Introduction}

In the previous paper (Ben-Asher et al. 2016) we presented an analytical model to simulate the variations of temperature with time and position downstream along a river. The goals of the present study were to use the Nam Song River as a case study for parameter determination and a comparison between the model and actual data.

After a construction of the diversion dam at Nam Song River, water shortage and extreme temperature increase affected the livelihood of living people downstream the Nam Song.

Water flow rate in the Nam Song River Basin, Mekong is decreased in the dry season. This decrease in the river discharge had a large impact on the fisheries and domestic water quality. The decline of fish catch was a serious loss to local villages and the river downstream of the dam now has far fewer species. The local people used to use the forest resources along the river before the dam was constructed but now many kinds of crops are transplanted along the riverbank to support the local people's lives, instead of fishery. The reduction of corridor vegetation density also accelerated the environmental changes in the vicinity of the Nam Song 
River (Roel and Sean 2001). One of the factors that are affected by these changes is the temperature of the water. Can it be controlled and maintained at an optimal level? To answer this question the predictive model describing the expected changes downstream may offer a practical tool for environmental maintenance.

\section{Materials and methods}

\section{Study area}

\section{The study area}

The region has tropical climate with two alternate seasons: dry and rainy. The dry season runs from November through April with minimum and maximum average temperatures around $23.5 \pm 1.9$ and $33.5 \pm 1.6^{\circ} \mathrm{C}$, respectively; average humidity about $65 \%$ and total rain range from 300 to $400 \mathrm{~mm}$. During the rainy season from May through October the respective average temperatures are $22.7 \pm 4.3$ and $32 \pm 1.1{ }^{\circ} \mathrm{C}$; relative humidity $75 \%$ and total rain from 1500 to $1700 \mathrm{~mm}$. This is the monsoon season. The annual mean temperature is $27.6 \pm 2.3$. It should be noted that the proximity to the equator results in a stable temperature with small changes throughout the year. It justifies the use of mean air temperature $\left(\bar{T}_{a}\right)$ in the model. However, on the other hand, under arid or cold regions it may require some modifications.

Nam Song River is tributary of Nam Ngum river and Nam Ngum river is tributary of Mekong river. During the study, meteorological and water temperatures were measured at the main stream of Nam Song river.

The Nam Song River, has a catchment area of $1800 \mathrm{~km}^{2}$ and length of $100 \mathrm{~km}$ (Fig. 1). A diversion Dam (catchment area of $1500 \mathrm{~km}^{2}$ ) was constructed in 1996 to divert water from the Nam Song basin to the Nam Ngum reservoir.

Downstream of the Nam Song Dam, there are eight villages consisting of approximately 4000 people along the riverbanks. In the dry season, the water release discharge from the Nam Song Dam decreases from $10.0 \mathrm{~m}^{3} \mathrm{~s}^{-1}$ to a minimum of only $2.0 \mathrm{~m}^{3} \mathrm{~s}^{-1}$ (Yoshida et al. 2004); the average flow velocity during the study period was $1800 \mathrm{~m} \mathrm{~h}^{-1}$.

\section{Measurement}

Stream and air temperatures were observed at a point located $4 \mathrm{~km}$ downstream (N1846 $123^{\prime \prime}$, E10224'00") from the Nam Song Dam.. Other meteorological factors such as humidity, wind speed, sunshine duration were measured at

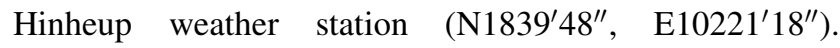

Fig. 1 The study area and the Num Song river

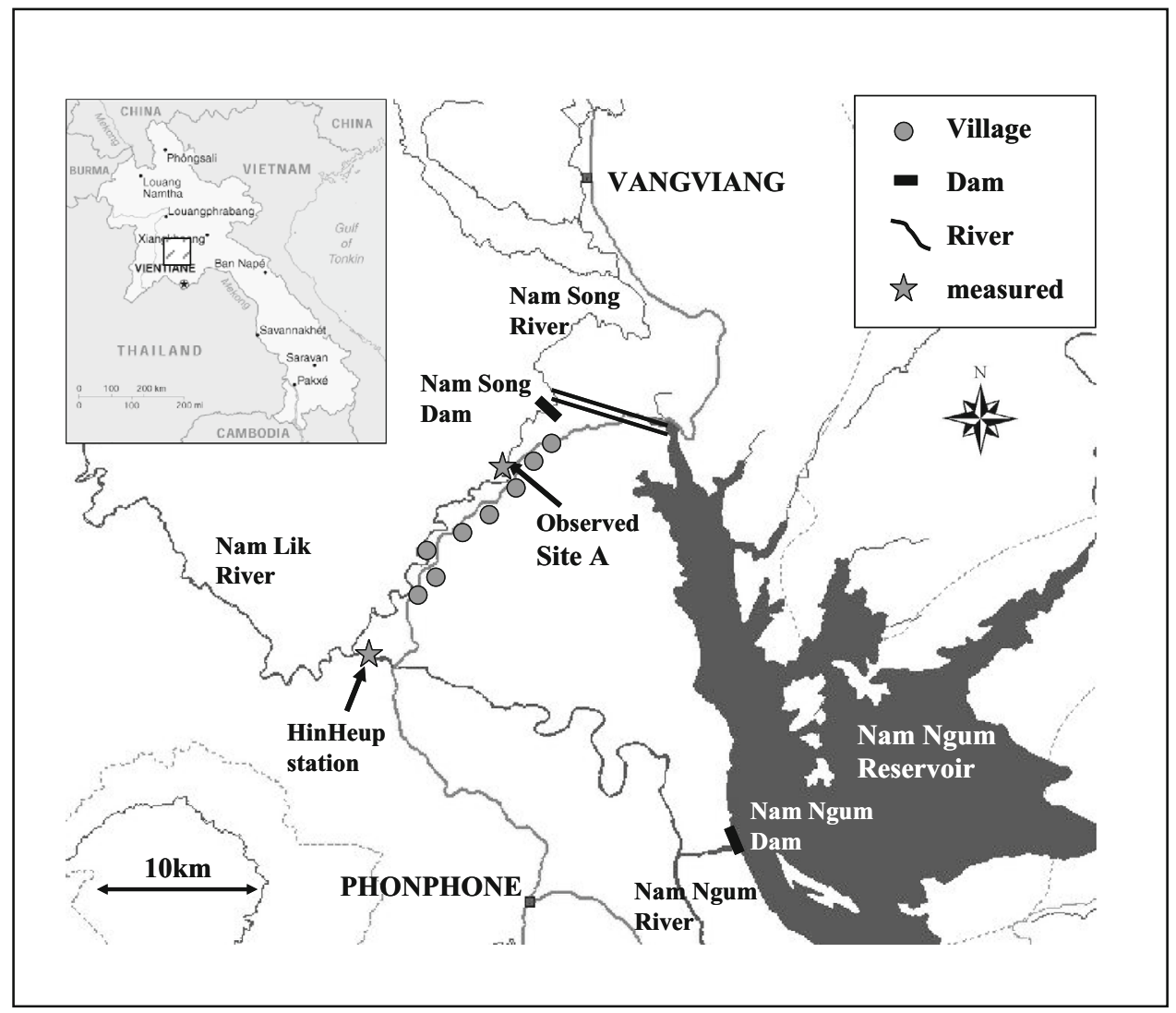


Thermometer (temperature range -20 to $70^{\circ}$, resolution $0.2^{\circ}$ ) was installed in the water $20 \mathrm{~cm}$ above the riverbed at the center of flow and measured water temperature every hour.

These set of measurements provided the following data that were used in our parameter estimations: (a) correlation between water temperature and time for heating and cooling. (b) The steady state temperature (c) The duration of each thermal cycle. These data were analyzed by derivatives of the mathematical approximations (BenAsher et al. 2016) and used to estimate the system's unknowns including the thermal time constant, the energy conversion parameters, the duration of the cycle and the water flow velocity. The last two parameters were measured during the study period but were also calculated by the model to compare measurements with their approximations.

\section{Data analysis}

The original measurements of the water thermal cycles stretched from March 162004 to March 252006 (Day 74-84) and included air and water temperature. The results of the measuring days were arranged in continuous consecutive fluctuations throughout the measuring period. To compare it with the model, we sliced the consecutive daily data on a $24 \mathrm{~h}$ basis. Each day started when the elapsed time was 0 and the water temperature was at its minimum. It stopped when the temperature was again at its minimum after $24 \mathrm{~h}$. This procedure created a family of sinusoidal curves of thermal variations from which we extracted the average temperatures at each point in time. The average values were used for the evaluation of the model parameters. Note that 1 day (DOY 80) was kept out of the averaging process for a comparison between model and measurements. Using the average values of the model parameters it was validated against a typical but independent thermal cycle (DOY 80) that was selected from the measured cycles as an indicator for the predictive ability of the model.

\section{Parameter estimations}

The model requires only three immeasurable parameters. They are the thermal time constant (" $k$ " per time units), the residual short wave radiation in thermal terms ( $a$ " ${ }^{\circ} \mathrm{C}$ per time) and an energy coefficient of proportionality ["Ke/h" $\mathrm{MJm}^{-3} \mathrm{~h}^{-1}$ )]. A major objective of the study was to develop a set of mathematical approximations of the river parameters. The parameters are based on the analytical model and experimental data and are useful for the proposed predictions.
Using the heating process to estimate the thermal time constant $(k)$

The basic equation to describe the short-time heating process is Eq. (16a) in the first paper (Ben-Asher et al. 2016) to describe the fluctuating curves

$$
\begin{aligned}
& Q(t)=\frac{\mathrm{Ke}}{h}\left(\bar{T}_{a}-\frac{\mathrm{a}}{\mathrm{k}}\right)\left[\left(t-t_{0}\right)-\frac{1-\mathrm{e}^{-k(t-t 0)}}{k}\right]+Q 0 ; \\
& \quad t \leq t_{0}+X / V
\end{aligned}
$$

This equation can be expanded in a taylor series

$$
\begin{aligned}
Q(t)= & \frac{\mathrm{Ke}}{h}\left(\bar{T}_{a}-\frac{a}{k}\right) \frac{1}{k} \times\left[\left(t-t_{0}\right) k-1+1-k\left(t-t_{0}\right)\right. \\
& \left.+\frac{k^{2}}{2}\left(t-t_{0}\right)^{2}-\cdots+\frac{k^{n}}{n}\left(t-t_{0}\right)^{2}\right] \\
= & \frac{1}{2} \frac{K e}{h}\left(\bar{T}_{a}-\frac{a}{k}\right) k\left(t-t_{0}\right)^{2}+Q 0
\end{aligned}
$$

where $\mathrm{Q}(\mathrm{t})$ is the total energy input into the water of the river $\left(\mathrm{MJm}^{-3}\right), k e$ is a coefficient of proportionality that combines the physical constants of sensible heat flux and exchange of long wave radiation $(\mathrm{H}$ in Eq. 8 and $\Delta \mathrm{L}$ in Eq. 10 in Ben-Asher et al. 2016) $h(\mathrm{~m})$ is a unit river depth, $k$ is the cooling rate parameter, often called the thermal time constant, that has dimensions of $t^{-1}$ and $a$ is the thermal expression of the residual short wave radiation $\left({ }^{\circ} \mathrm{C} /\right.$ t). $\overline{T a}, T_{\mathrm{w}}$ and $T_{\mathrm{w} 0}$ are the respective average air temperature, the water temperature at any time and at the beginning of the heating process. Equation (2) indicates that for short times $T_{\mathrm{w}}(\mathrm{Q}, \mathrm{t}, \mathrm{X})$ depends quadratically on time (after conversion of the energy term into thermal term), as indeed found in our temperature measurements at the Nam Song River Basin. It is given as a polynomial line connecting between the measured points in Fig. 2.

The quadratic section of the rising limb in Fig. 2 starts at $t=1$ and last until about $t=4$. At $t=4$ the linear section of the rising limb starts but it is still within the range of the short time integral (Eq. 1). In this section the exponential value is negligible and the time dependence of $\Delta T_{w}(t)$ is approximately linear.

$$
\begin{aligned}
\Delta T_{\mathrm{w}}(\mathrm{t}) & =T_{\mathrm{w}}(t)-T_{\mathrm{w} 0} \\
& =\frac{K e}{\rho \operatorname{Cp} h} \times\left(\bar{T}_{a}-\frac{a}{k}\right) \times\left[t-t_{0}-\frac{1}{k}\right]
\end{aligned}
$$

where $\rho$ is the water density $\left(1000 \mathrm{~kg} \mathrm{~m}^{-3}\right), C p$ is the heat capacity of water $\left[=4.186 \mathrm{~kJ}\left(\mathrm{~kg}{ }^{\circ} \mathrm{C}\right)^{-1}=4.186 \mathrm{MJ}\right.$ $\left(1000 \mathrm{~kg}{ }^{\circ} \mathrm{C}\right)^{-1}$ ], and $\Delta \mathrm{T}_{\mathrm{w}}(\mathrm{t})$ is the change in water temperature $\left({ }^{\circ} \mathrm{C}\right)$.

Equation (3) was used to estimate the thermal time constant " $k$ " experimentally as demonstrated in Fig. 2. The extrapolation of the linear segment in this graph intercepts the time axis at $t=t_{0}+1 / k$. That is, the time interval 


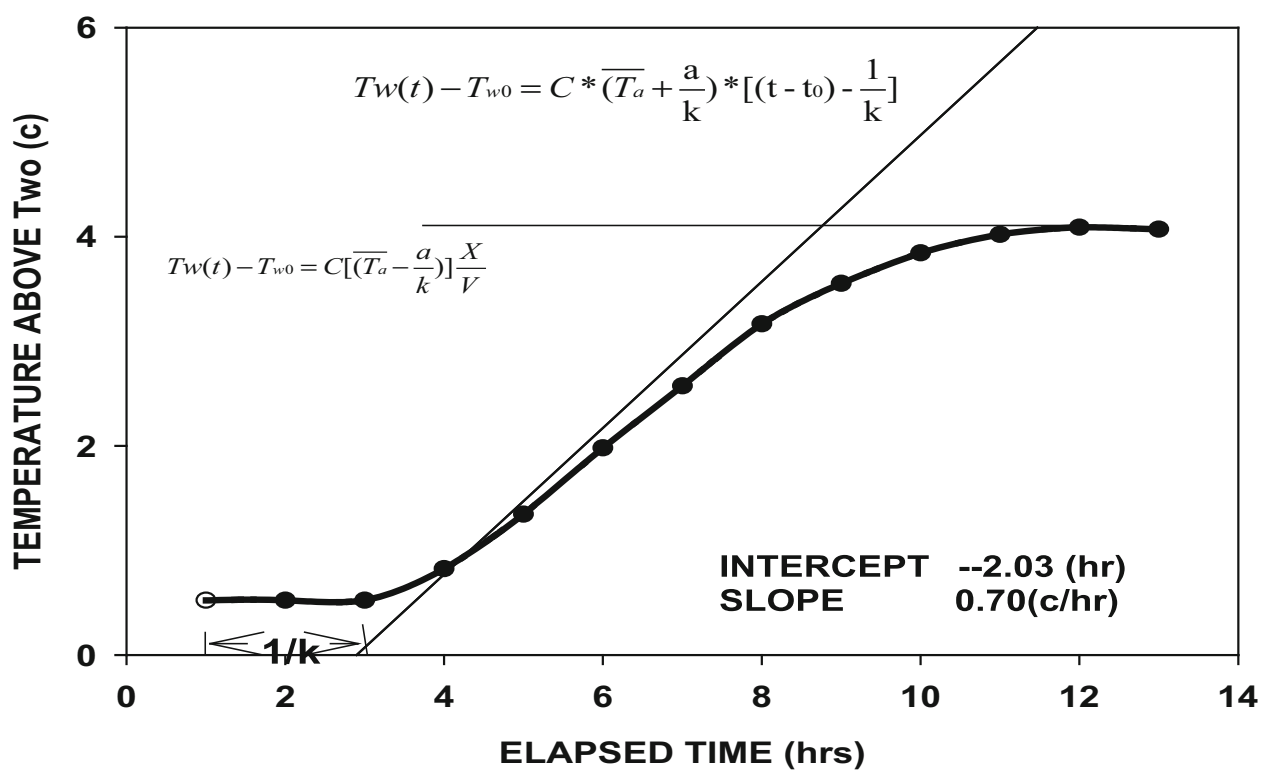

Fig. 2 A presentation of the measured water heating process (circled points) and its application for parameter estimation. The measured temperature followed the heavy solid line in which from Eq. 3 $\frac{K e}{\rho \mathrm{Cp} h}=$ constant $(\mathrm{C})$. The extrapolation of the linear segment in this graph intercepts the time axis at $t=t_{0}+1 / k$. The time interval between the starting point of the heating process $t_{0}$ and that of the linear approximation is equal to $1 / k$, from which $k$ can be found. From the time at which the horizontal line is crossing the linear slope one can estimate the stream flow rate for a known $(X=L)$ distance downstream
Table 1 The model parameters, estimated from measured data and approximated solutions

\begin{tabular}{llll}
\hline Parameters & Equations/Figure & Estimated/measured value & Units \\
\hline$k$ & Eq. (3)/Fig. 2 & 0.53 & $\mathrm{~h}^{-1}$ \\
$k$ & Eq. (9)/Fig. 2 & 0.25 & $\mathrm{~h}^{-1}$ \\
Average $k$ & & 0.39 & $\mathrm{~h}^{-1}$ \\
$V$ & Eq. (10)/Fig. 2 & $1130 / 1600$ & $\mathrm{mh}^{-1}$ \\
$T$ & Eq. (6)/Fig. 3 & $24.8 / 24$ & $\mathrm{~h}$ \\
Ke/h $\left(T_{a}-a / k\right)$ & Eq. (6)/Figs. 2 and 3 & 7.0 & $\mathrm{MJm}^{-3} \mathrm{~h}^{-1}$ \\
$a=$ & Eqs. (5, 6)/Fig. 3 & 13.1 & ${ }^{\circ} \mathrm{C} \mathrm{h}^{-1}$ \\
$a / k=$ & Eqs. (5, 6)/Fig. 3 & 33.5 & ${ }^{\circ} \mathrm{C}$ \\
$k e / h$ & Eqs. (5, 6)/Fig. 3 & -2.0 & $\mathrm{MJm}^{-3} \mathrm{~h}^{-1}{ }^{\circ} \mathrm{C}$ \\
$D$ & Eq. (6)/Fig. 3 & 4.2 & ${ }^{\circ} \mathrm{C}$ \\
$B$ & Eq. (6)/Fig. 3 3 (6)/Fig. 3 & -0.33 & ${ }^{\circ} \mathrm{C} \mathrm{h} \mathrm{h}^{-1}$ \\
$r^{-2}$ & Eq. & 0.99 & - \\
Constant & Eq. (3)/Fig. 2 & 2.03 & ${ }^{\circ} \mathrm{C}$ \\
Slope & Eq. (3)/Fig. 2 & 0.7 & ${ }^{\circ} \mathrm{C} \mathrm{h}^{-1}$ \\
$r^{-2}$ & Eq. (3)/Fig. 2 & 0.99 & - \\
\hline
\end{tabular}

The list of estimated data was used in the comparison between the model and the measured water temperature between the starting point of the heating process $t_{0}$ and that of the linear approximation is equal to $1 / k$, from which $\mathrm{k}$ can be found. This approximation is also displayed in Fig. 2 as a linear line and the results are in Table 1.

The relationship between water temperature and energy is obtained from the product of water temperature and its heat capacity $\left(\rho \mathrm{Cp}=4.186 \mathrm{MJm}^{-3}{ }^{\circ} \mathrm{C}^{-1}\right)$. Equation (1) satisfies the conditions that at $t=t_{0}$ at any position $\mathrm{X}$ the added amount of energy $\left(Q-Q_{0}\right)$ to the water is zero and the amount of energy stored in the water is $Q_{0}$. ke is an energy term $\left(\mathrm{MJm}^{-2} \mathrm{~h}^{-1} \mathrm{~K}^{-1}\right)$ which is per unit river depth (h) $\mathrm{Ke} / \mathrm{h}$ has the dimensions of $\mathrm{MJm}^{-3} \mathrm{~h}^{-1}{ }^{\circ} \mathrm{C}^{-1}$. The ratios $(K e / h) / \rho \mathrm{Cp}$ and $T_{\mathrm{w}}=Q / \rho \mathrm{Cp}$ are used to convert the energy terms in Eq. (2) into water temperature terms, 
Using the cooling process for determination of the duration of the thermal cycle

As determined in Eq. (21) of the previous paper (BenAsher et al. 2016) beyond $t=t_{\mathrm{r}}$ the thermal equivalent of $Q, \quad T_{\mathrm{w}}(t)$ decreases with time at a known position $X=L$ according to Eq. (4)

$$
\begin{aligned}
\Delta T_{\mathrm{w}}(t, L)= & \frac{K e}{\rho \mathrm{Cp} h}\left(\bar{T}_{a}-\frac{a}{k}\right) \frac{L}{V} \\
& -\frac{K e}{\rho \operatorname{Cp} h}\left[\left(\bar{T}_{a}-\frac{a}{k}\right)+\Delta \mathrm{T}_{\mathrm{wm}}\right]\left(t-t_{\mathrm{r}}\right)
\end{aligned}
$$

where $\Delta \mathrm{T}_{\mathrm{wm}}$ is the difference between maximum and initial (minimum) water temperature, $t_{\mathrm{r}}$ marks the end of the heating process and the start of the cooling process, when the water temperature is at its daily maximum and $T^{*}$ marks the end of the thermal cycle (heating and cooling process).

The end of the heating process which is the start of the cooling process occurs at time $t_{\mathrm{r} .}$. It is a function of the position $\mathrm{X}$ along the river. Therefore, it is the time to obtain the lowest river temperature $\left(T_{\mathrm{w} 0}\right)$.

In terms of temperature the cooling process at $X=L$ can be written as a linear function of time:

$T_{w}\left(t_{r} \leq t \leq T *\right)-T_{\mathrm{w} 0}=D-B\left(t-t_{\mathrm{r}}\right)$

where $D=\frac{L}{V} \frac{k e}{h}\left[\left(\bar{T}_{a}-\frac{a}{k}\right)\right] / \rho \mathrm{Cp}$ and $B=-\frac{k e}{h}\left[\left(\bar{T}_{a}-\frac{a}{k}\right)+\right.$ $\left.\Delta \mathrm{T}_{\mathrm{wm}}\right] / \rho \mathrm{Cp}$.

This solution satisfies the conditions that at $t=t_{r}$ at any position $X$ the first term in the right hand side of Eq. (5) represents the steady-state thermal conditions when $T_{\mathrm{w}}$ is at its maximum. Beyond $t=t_{\mathrm{r}}, T_{\mathrm{w}}(t)$ decreases with time at a rate given by $\mathrm{B}$.

The next parameter that should be estimated to run the model is the product $\frac{k e}{h}\left(\bar{T}-\frac{a}{k}\right)$. Although it contains two unknowns $\frac{k e}{h}$ and $\frac{a}{k}$ it appears as a single unknown in all three solutions of the thermal cycle (short-time heating, longertime heating and the cooling stage). Equations (16a, 16b, 21) in Ben-Asher et al. (2016). One way to estimate the constant $\frac{k e}{h}\left(\bar{T}-\frac{a}{k}\right)$ is from the intercept of Eq (5) with $\Delta T_{\mathrm{w}}$ axis which determines the steady state conditions.

The time to obtain $T_{\mathrm{w} 0}$, is $T^{*}(X)$ which marks the end of the entire daily cycle (heating and cooling process).

Equations $(4,5)$ suggests that for each point $X$, there is time $T^{*}(X)$ at which the cooling process ends and water temperature is at its minimum $\left[T_{\mathrm{w}}(t)=T_{\mathrm{w} 0}\right]$ and $\Delta T_{\mathrm{w}}=0$. That is, close to the dam the thermal cycle is short relative to its duration away from the dam. Another consequence of the equations is that the thermal depletion can be described by a linear function of time and it stretches between $t_{\mathrm{r}}$ and $T^{*}$. It is given by the slope B and the intercept which can be obtained from a regression analysis of the observed $\mathrm{T}_{\mathrm{w}} \mathrm{vs}$. elapsed time during the cooling stage.
For the measuring point $X=L^{\prime} T$ is given by:

$T *(L)=t_{\mathrm{r}}+\frac{D}{B}$

Thus, when $T_{\mathrm{w}}\left(t=t_{\mathrm{r}}\right)$ and $t_{\mathrm{r}}$ values are collected by routine measurements the time to end the diurnal cycle $\left(T^{*}\right)$ can be calculated from the regression analysis in Fig. 3 and Eq. (6).

The linearity of the cooling phase is easily depicted from the data points in Fig. 3 and the associated regression line with $r^{2}=0.99$. The time to end the thermal cycle was about $25 \mathrm{~h}$ and the data to calculate it are given in Fig. 3 .

\section{Using the heating and the cooling processes to estimate} the water flow velocity $(V)$

When $t=t_{\mathrm{r}}$ in Eqs. $(4,5)$ the solution becomes independent of time. Thus, for a constant velocity which is measured at $X=L$ its value is given by:

$T_{\mathrm{w}}=\frac{k e}{h \rho \mathrm{Cp}}\left[\left(\bar{T}-\frac{a}{k}\right)\right] \frac{L}{V}+T_{\mathrm{w} 0}$

This solution is shown in Fig. 2 by the horizontal steadystate temperature that was measured during the study period. The linear limb of the heating process (Eq. 3), if extrapolated to longer $t$, intersects the steady state value of $T_{\mathrm{w}}$ at a time:

$t=t_{0}+\frac{1}{k}+\frac{L}{V}$

Equation (8) can be used to calculate $1 / k$. Having $V$ actually measured at $X=L=4000 \mathrm{~m}$ the term: " $t_{0}+1 / k$ "

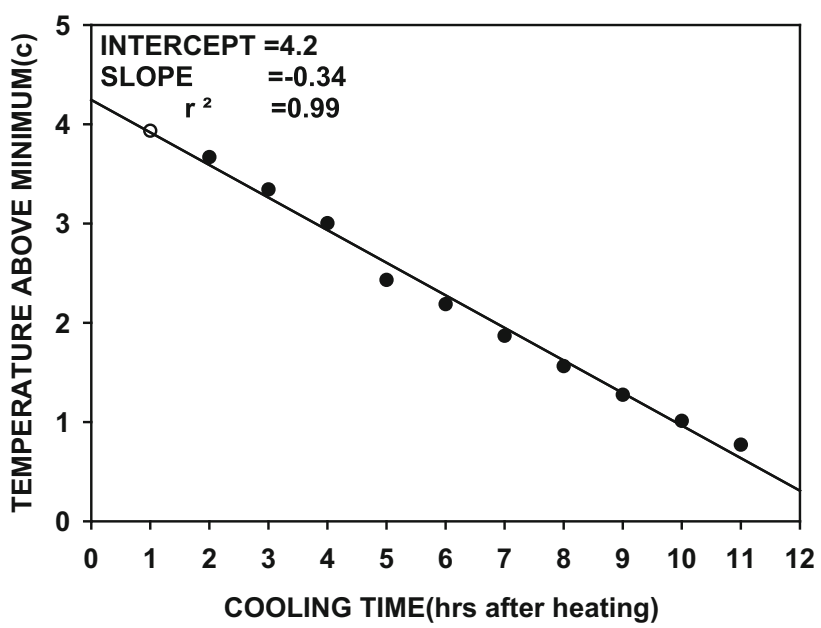

Fig. 3 A linear presentation of the measured water cooling process. The measured points display the declined difference between maximum and minimum water temperature. The solid line is the linearized solution for parameter estimation and its associated regression analysis 
can be taken from the interception in Eq. (3). Alternatively, when $t$ is approximated from Fig. 2 and $V$ is an unknown we can estimate it from

$V=\frac{L}{t-t_{0}-\frac{1}{k}}$

In Table 1 we summarized the estimated values of all the parameters that are required and used to run the model. Note in Table 1 that the estimated $V$ was about $30 \%$ smaller than the measured $1600 \mathrm{mh}^{-1}$. The parameter $a / k$ that integrates all energy residuals in terms of temperature was $3{ }^{\circ} \mathrm{C}$ larger than the air temperature. It certainly
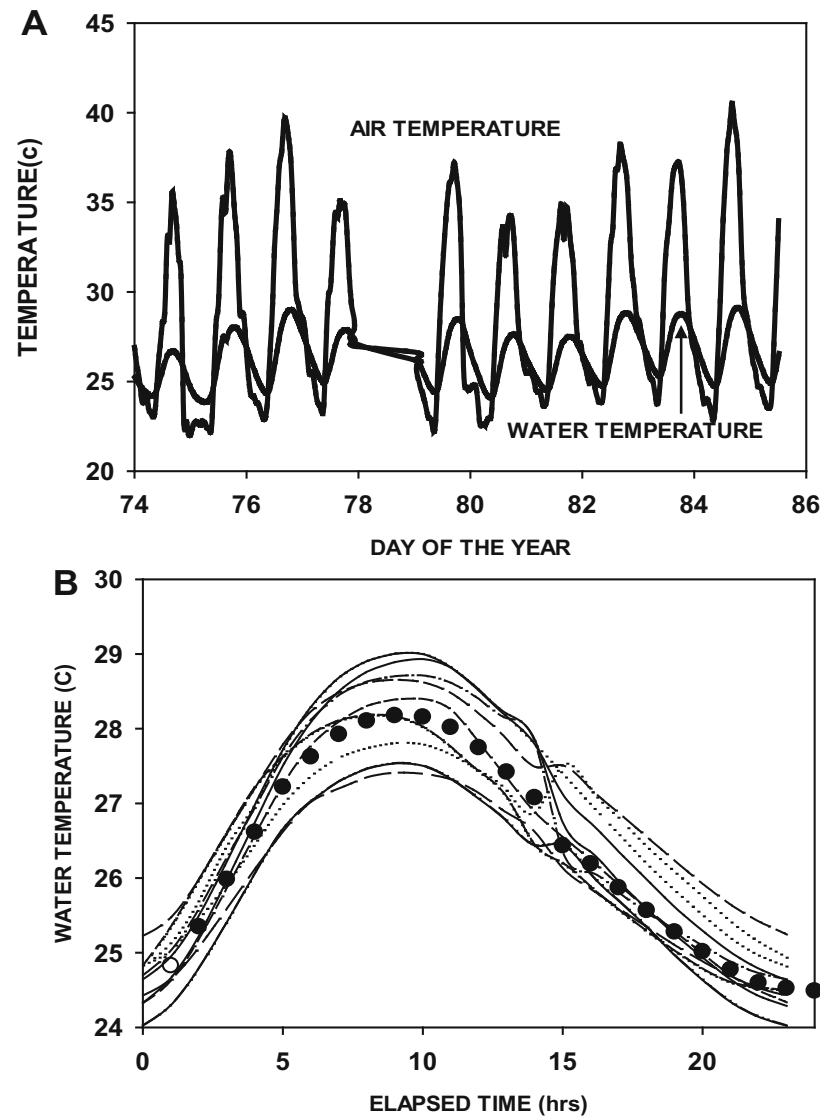

Fig. 4 a Thermal cycles as a function of day of the year from March 16 to March 25. The upper line is the air temperature and the lower line (marked by an arrow) is the water temperature. b The same thermal cycles presented as a function of elapsed time from 0 at minimum temperature to $24 \mathrm{~h}$ again at minimum temperature. The average value is marked by black dots indicates its importance in the energy balance of the river. The thermal time constant, in Table 1 was estimated by two different approximations and hence yielded two values from which we extracted an average.

\section{Results and discussion}

All measured thermal cycles are presented in Fig. 4.

As can be seen from inspection of the individual cycles (Fig. 4a), the heating starting time $t_{0}$ and the peak water temperature are dependent on air temperature. The lower the air temperature the lower is the peak water temperature.

The onset time of peak water temperature was similar in all thermal cycles independent of air temperature (Fig. 4b).

The nature of the cooling stage is very similar on all measuring days (Excluding short times on irregular days). They appear as a family of parallel lines (Fig. 4b) that decrease at a moderate rate (compare to the heating stage) the moment the heating stops. The time to complete the thermal cycle $\left(T^{*}\right)$ depends on the peak water temperature as predicted by Eq. (6). The higher the peak, the longer is the thermal cycle. Naturally, the amount of energy stored in a volume element of the river at its peak varies according to the water temperature. Under conditions of constant cooling rate (Eq. 5) the larger the energy stored in the water the longer the cooling stage as observed in Fig. 4b.

The parameters estimated on the basis of the analysis are given in Table 1. From this table, only three immeasurable parameters should be estimated to run the model. They are the thermal time constant " $k$ ", the residual energy source (or sink) " $a$ " and the energy coefficient of proportionality $\mathrm{Ke} / \mathrm{h}$. The last term includes the effective depth of the river.

The comparison between the measured and predicted water temperature was based on the above parameters that were estimated from the average cycle of all measuring days (the full circles in Fig. 4b. They are summarized in Table 2.

The top lines display five measurable parameters and the bottom two lines display the three immeasurable parameters. The estimation of these parameters was based on the mathematical derivations of the model. Note in Table 2 that the estimated $V$ was about $30 \%$ smaller than the measured $1600 \mathrm{mh}^{-1}$. The parameter a/k that integrates all energy residuals in terms of temperature was $3{ }^{\circ} \mathrm{C}$ above the air temperature. The thermal time constant in Table 2
Table 2 List of parameters that were used to run the model

\begin{tabular}{llllll}
\hline Measured parameters (units) & $\mathrm{L}(\mathrm{m})$ & $\mathrm{V}(\mathrm{m} / \mathrm{h})$ & $\mathrm{Ta}\left({ }^{\circ} \mathrm{C}\right)$ & $\mathrm{T}_{\mathrm{w} 0}$ & $\mathrm{~T}_{\mathrm{wmax}}$ \\
\hline Value & 4000 & $1600 / 1130$ & 30 & 24 & 28 \\
Estimated parameters (units) & $\mathrm{Ke} / \mathrm{h}\left(\mathrm{MJm}^{-3} \mathrm{~h}^{-1}{ }^{\circ} \mathrm{C}^{-1}\right)$ & $k\left(\mathrm{~h}^{-1}\right)$ & $a / k\left({ }^{\circ} \mathrm{C}\right)$ & & \\
Value & 2.0 & 0.39 & 33.5 & & \\
\hline
\end{tabular}




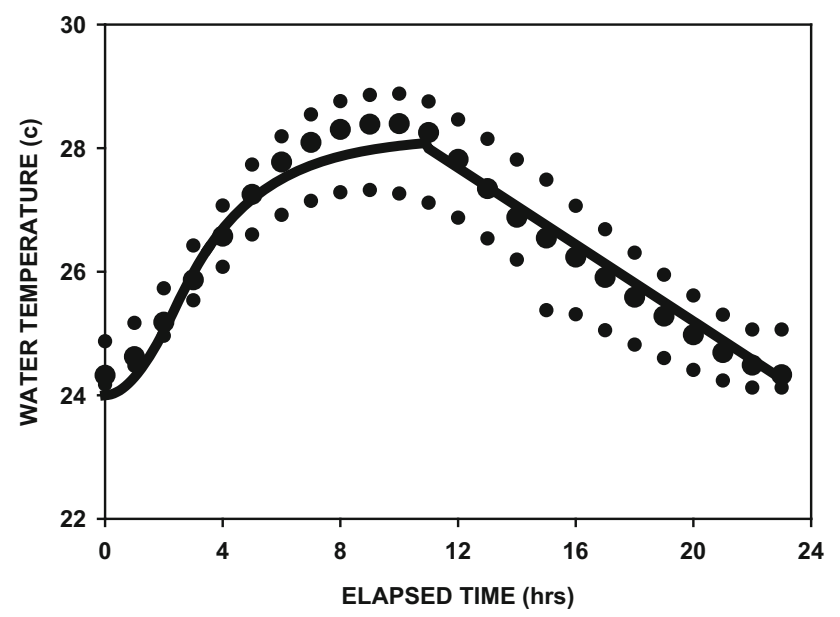

Fig. 5 Predicted and measured temperature as a function of elapsed time. Measured thermal cycle marked by heavy dotes (day 80) and the prediction (solid line) is based on estimated parameters from the average cycle. Top and bottom envelopes mark the boundaries of the standard deviation

was estimated by two different approximations and hence yielded two values from which we extracted an average.

The results of the comparison are given in Fig. 5 .

The model data for changes in temperature as a function of elapsed time agreed with the measured values both quantitatively and qualitatively. The predicted values of the thermal cycle did not exceed the envelope boundaries but were several tenths of a degree lower than the measured peak values. This satisfactory agreement between measured and calculated lines in Fig. 5 would appear to indicate that the approximations of the mathematical solutions for parameter estimation are reasonable. This good agreement between calculated and independent measured temperatures using the prescribed method of estimation yields a positive conclusion as to the predictive ability of the model.

\section{Conclusions}

The model requires three immeasurable parameters: the thermal time constant (" $k$ " per time), the residual short wave radiation in thermal terms ( " $a$ " ${ }^{\circ} \mathrm{C}$ per time), and an energy coefficient of proportionality ["Ke/h" $\mathrm{MJm}^{-3}$ $\left.\mathrm{h}^{-1}\right)$ ]. A major objective in this study was to develop a set of mathematical approximations that are based on the analytical model and experimental data and are useful for parameter estimations.

This approach also points out a simple way to identify the major system parameters that govern the rate of thermal fluctuations in the river.

The successful comparison between theoretical prediction and measured temperature indicates that the model can be used for managing different aspects of river environment. The thermal environment of the river-dam-atmosphere system can be controlled and optimized by $V$, provided the three system parameters, $K e / h, a$, and $k$, are known. The river flow rate $V$ can be optimized through a controlled release of water from the dam. This is probably the most important variable that can be used to control the proper distribution of temperatures along the river.

Bearing in mind that concentration of dissolved oxygen is strongly affected by temperature, oxygen depletion is about $0.23 \mathrm{ppm} / 1{ }^{\circ} \mathrm{C}$ increase in temperature (Kondo 1995). Fluctuations of $3-4{ }^{\circ} \mathrm{C}$ in maximum temperature may be associated with a loss of 9-10\% of the oxygen content in the river water with harsh environmental consequences. Thus, there are several processes within a stream that are affected by its temperature and provide the rationale for this study.

Acknowledgments This study was funded by the Ministry of Science and technology, Israel; Research Institute for Humanity and Nature (RIHN) under the project: Impact of Climate Change on Agriculture Productivity (ICCAP) in Kyoto and CREST of the Japan Science and Technology Agency. Japan. In addition, funding was received from two Grant-in-Aids: Revolutionary Researches 2002 of the Israel Ministry of Education, Science, Sports and Culture.

\section{References}

Ben-Asher J, Yoshida K, Shiozawa S (2016) Thermal variations of water in the Nam Song stream/Mekong river: I. A mathematical model. Sustain Water Resour Manag. doi:10.1007/s40899-0160044-9 (this issue)

Kondo Y (1995) Diurnal temperature variations of the river water I model. J Jap Soc Hydrol Water Res 8:184-196

Roel S, Sean W (2001) Nam Song diversion project ADB TA5693Draft impact analysis report and action plan. Asian Development Bank. October 2001

Yoshida K, Tanji H, Somura H (2004) Stream flow analysis in Num Ngum River Basin, Mekong. Ann J Hydrol Eng JSCE 48:1531-1535 